EESTI NSV TEADUSTE AKADEEMIA TOIMETISED. VI KOIDE

BIOLOOGILINE SEERIA. 1957, NR. 4

ИЗВЕСТИЯ АҚАДЕМИИ НАУК ЭСТОНСКОЙ ССР. ТОМ VI

СЕРИЯ БНОЛОГИЧЕСКАЯ. 1957, № 4

\title{
SIGADE PUNATAUDI TEKITAJATE TUVEDE SEROLOOGILISEST UURIMISEST
}

\author{
V. TILGA, \\ veterinaariateaduste kandidaat
}

Sigade punataudi tõrje efektiivsus sõltub punataudivastaseks aktiivseks ja passiivseks immuniseerimiseks kasutatavatest vaktsiinidest ja seerumitest, mille immuniseerivad omadused olenevad peamiselt nende valmistamiseks kasutatud Erysipelothrix rhusiopathiae tüvede immunogeensetest omadustest.

Erysipelothrix rhusiopathiae tüvede valik vaktsinide ja seerumite valmistamiseks on seotud teatud raskustega, sest punataudi surnud sigadelt isoleeritud tüved immuniseerivad enamasti kas ainult nōrgalt vōi üldse mitte $[1,2,3,4,6$ jt.]. Et tōsta punataudivastaste vaktsiinide ja seerumite immuniseerimisvöimet, soovitavad mitmed autorid $\left[1,2,3,{ }^{4}\right.$ jt.] kasutada nende valmistamiseks korraga rohkem tüvesid. Uurimiste põhjal [4 jt.] on Erysipelothrix rhusiopathiae S-vormi tüved suuremate immunogeensete omadustega kui nende R-vormi tüved. Paljud autorid peavad tüvede immunogeensete omaduste esinemist sōltuvaks tüvede virulentsusest. Nii näiteks märgib Butšnev [1], et formoolvaktsiini valmistamiseks tuleb kasutada vaid virulentseid tüvesid. Gorlov [4] see. vastu väidab, et immunogeensed omadused tüve virulentsusest ei sōltu.

Kuni 1940. aastani puudusid andmed Erysipelothrix rhusiopathiae tüvede seroloogiliste ja immunobioloogiliste omaduste erinevuste kohta ja köigi nende tüvede antigeenset struktuuri peeti ühtlaseks [7]. Erysipelothrix rhusiopathiae tüvede antigeense struktuuri erinevusi kirjeldas esimesena Watts [15], kes uuris aglutinatsioonireaktsiooniga 43 punataudi tekitaja tüve mitmelt Euroopa maalt, Ameerikast ja Jaapanist. Watts leidis, et uuritud tüved jagunevad oma antigeensete omaduste poolest kahte täiesti erinevasse seroloogilisse rühma. Neist ühte antigeeni tüüpi kuulus 43-st uuritud Erysipelothrix rhusiopathiae tüvest 38 ja teise 5 tüve. Ei esinenud mingit seost tüvede seroloogilise rühma ja nende virulentsuse vahel.

Dedié $\left.{ }^{[7}\right]$ uuris pretsipitatsiooni-, aglutinatsiooni- ja komplemendisidumisreaktsiooni abil küülikutelt saadud immuunseerumitega sada Erysipelothrix rhusiopathiae tüve $\mathrm{ja}$ leidis samuti kaks gruppi antigeene, mille põhjal ta paigutas 55 tüve nn. A-varianti ja $37 \mathrm{nn}$. B-varianti; 8 tüve aga, millel ei olnud spetsiifilist antigeeni, arvas ta nn. N-variantide hulka. Iljašenko [ $\left.{ }^{[}\right]$uuris aglutinatsiooni- ja pretsipitatsioonireaktsiooniga neljakümmend punataudi tekitaja tüve, kusjuures tema samuti jagas uuritud tüved nende seroloogilise aktiivsuse järgi 3 gruppi. Iljašenko andmeil on A-grupi tüved seroloogiliselt aktiivsed ja tugevate immunogeensete omadustega (Dedié' järgi B-grupi tüved), kuna B-grupi tüved on seroloogiliselt vähe aktiivsed ja vähe immunogeensed (Dedié' järgi A-grupi tüved) ja V-grupi tüved seroloogiliselt inaktiivsed ja mitteimmunogeensed (Dedié' järgi N-grupi tüved). Tugevate immunogeensete omadustega A-grupi tüvesid oli Iljašenkol ainult 5, kuna ülejäănud kuulusid kas B-vōi V-gruppi. Parimaks immunogeensete tüvede väljavalimismeetodiks peab Iljašenko pretsipitatsioonireaktsiooni.

Hirst [11] kirjeldas esimesena viiruste (influentsa) omadust aglutineerida mitmesuguste loomade ja lindude erütrotsüüte. Seda omadust on teadlased kasutanud ka mitmète mikroobiliikide uurimiseks. Hemaglutineerivate omaduste esinemist Erysipelothrix rhusiopathiae tüvel märkis esimesena Dinter ${ }^{\left[{ }^{8}\right]}$ ja kirjeldas 3 erineva Erysipelothrix rhusiopathiae tüve uurimisest hemaglutinatsioonireaktsiooniga, kusjuures üks tüvi aglutineeris kana erütrotsüütidega ja 2 tüve mitte. Seda hemaglutineerivat omadust sai autor takistada vaid punataudivastase seerumi lisandamisega, kuna teised seerumid (näit. difteeriaseerum) sellist mõju ei avaldanud.

Järgnevalt teatas Dinter [ $\left.{ }^{9}\right]$, et olles uurinud hemaglutinatsioonireaktsiooniga 70 Erysipelothrix rhusiopathiae tüve, leidis ta ainuit kuuel pidevalt hemaglutineerivat omadust, kuna ülejäänud hemaglutineerisid kas ainult nōrgalt vôii üldse mitte. Edasi leidis Dinter, et ainult hemaglutineerivatest tüvedest valmistatud adsorbaatvaktsiinidel on valgete hiirte suhtes kõrge immuniseeriv võime ja seega osutub hemaglutinatsioonireaktsioon lihtsaks meetodiks punatauditekitaja tüvede väljavalimiseks vaktsiinide valmistamise jaoks. 
Szent Iványi [14], uurinud 505-t erinevatest Ungari maakohtadest pärinevat Erysipelothrix rhusiopathiae tüve nii hemaglutinatsiooni- kui ka pretsipitatsioonireaktsiooniga, leidis, et neist ei hemaglutineerinud 324 tüve $(64,1 \%)$, kuuludes Dedié' $\left.{ }^{7}\right]$ järgi A-varianti, ja hemaglutineeris 177 tüve $(35,0 \%)$, kuuludes pretsipitatsioonireaktsiooni järgi B-varianti. 4 vana laboratooriumitüve ei hemaglutineerinud ja ei omanud ka kumbagi spetsiifilist antigeenstruktuuri (nn. N-tüved). Roots ja Venske ${ }^{[3]}$ ning Radvila $\left.{ }^{12}\right]$ on tōendanud Szent Iványi $\left.{ }^{[14}\right]$ uurimistulemusi.

Nagu kirjanduse andmetest selgub, jagunevad Erysipelothrix rhusiopathiae tüved pretsipitatsioonireaktsiooni pōhjal mitmesse seroloogilisse gruppi, kusjuures tugevalt immuniseerivaid omadusi on ainult nn. B-grupi tüvedel (Iljašenko järgi A-tüved) $[?, 10]$. Neid B-grupi tüvesid on vōimalik kergesti kindlaks määrata hemaglutinatsioonireaktsiooni abil $[13,14]$.

Kuna meil puuduvad konkreetsed andmed isoleeritud Erysipelothrix rhusiopathiae tüvede antigeenstruktuuri ja hemaglutineerivate omaduste kohta, siis käesoleva töö raamides uuriti punataudi surnud vôi hädatapetud Eesti NSV päritoluga sigadelt isoleeritud Erysipelothrix rhusiopathiae tüvede vastavaid omadusi. Kokku uuriti 110 Erysipelothrix rhusiopathiae tüve.

\section{Metoodika}

Hemaglutinatsiooniks kasutati vaid sigade punataudi tekitaja S-vormiga tüvesid. Kuna need aga bakterioloogilistel söötmetel kasvatamisel kalduvad kergesti R-vormile, siis kasvatati iga tüve enne reaktsiooni läbiviimist trüptoonpuljongis nelja- kuni viiekordse ümberkülvamisega iga 24 tunni järel, mille tagajärjel tüved omandasid vaid S-vormi.

Hemaglutinatsioonireaktsiooni läbiviimiseks kasvatati Erysipelothrix rhusiopathiae tüvesid 20-96 tundi $2 \%$-lises lihapeptoonpuljongis, millele oli lisatud $10 \%$ hobusevereseerumit. Erütrotsüütidena kasutati steriilse füsioloogilise keedusoolalahusega kolm korda pestud ja tsentrifuugitud $1 \%$-list kana erütrotsüütide suspensiooni.

Katseteks kasutati $8 \mathrm{~mm}$ läbimōōduga steriilseid katseklaase ja igast uuritavast mikroobikultuurist tehti steriilse füsioloogilise keedusoolalahusega lahjendid $1: 2,1: 4,1: 8$, $1: 16$ ja $1: 32$. Igasse katseklaasi pandi $0,5 \mathrm{ml}$ mikroobikultuuri lahjendit ja $0,5 \mathrm{ml} 1 \%$-list kana erütrotsüütide suspensiooni. Segu loksutati hästi ja reaktsiooni loeti pärast poolekuni ühetunnilist seismist toatemperatuuris. Reaktsioonide kontrollidena kasutati kana erütrotsüütide suspensiooni ja füsioloogilist keedusoolalahust ning kana erütrotsüütide suspensiooni ja kasutatud söödet.

Hemaglutinatsioonireaktsiooni vōib edukalt läbi viia ka nōgususega esemeklaasil, kusjuures vastavat mikroobikultuuri lahjendit ja kana erütrotsüütide suspensiooni vōetakse $0,05 \mathrm{ml}$. Reaktsiooni vōib sel puhul lugeda juba umbes 10 minuti pärast.

Reaktsiooni hinnati järgmiselt: $++++=$ väga tugev, $+++=$ tugev, $++=$ $=$ keskmiselt tugev, $+=$ nōrk ja $-=$ negatiivne. Hemaglutineerivaks loeti sellised Erysipelothrix rhusiopathiae tüved, mille mikroobikultuuri lahjend 1:8 tugevasti ja 1:16 keskmise tugevusega vōi nōrgalt aglutineerus.

Küülikute immuniseerimiseks kasutatud antigeen valmistati Szent Iványi $\left.{ }^{14}\right]$ poolt soovitatud viisil järgmiselt. Väljavalitud Erysipelothrix rhusiopathiae tüvede 48-tunnilised puljongkultuurid tsentrifuugiti, sadet pesti steriilse füsioloogilise lahusega ja tsentrifuugiti uuesti. Pealmine vedelik valati ära ja järelejäänud sademele lisandati steriilset $0,4 \%$-list formaliinilahust, kuni sademe tihedus vastas $97 \mathrm{ml} 1 \%$-lise väävelhappe ja $3 \mathrm{ml}$ $1 \%$-lise baariumkloriidi segu tihedusele. Saadud segu hoiti 24 tundi termostaadis $37^{\circ} \mathrm{C}$ temperatuuris. Pärast seda tehti temast veriagarplaatidele külvid, mille pōhjal kontrolliti, kas mikroobid valmistatud antigeenis on surnud.

Saadud nn. surmatud antigeeni süstiti küülikutele iga nelja päeva tagant $1-4 \mathrm{ml}$ kōrvaveeni ja siis kaks korda samade ajavahemikkude järel $1-2 \mathrm{ml}$ samade tüvede elavkultuuri suspensiooni. Siis peeti $6-7$ päeva vahet, kontrolliti küülikutel seerumi tiitrit ja kui see oli küllaldane, lasti küülikud verest tühjaks. Steriilsetesse klaasnōudesse kogutud verest eraldati järgmisel päeval seerum steriilsetesse klaaspudelikestesse ja neid hoiti alal külmutuskapis, kus temperatuur oli $+4^{\circ} \mathrm{C}$.

Pretsipitatsioonireaktsiooni jaoks vajaliku antigeeni saamiseks kasvatati mikroobi tüvesid lihapeptoonpuljongis, millele oli lisandatud $10 \%$ hobusevereseerumit. Pärast 24-tunnilist termostaadis kasvatamist tsentrifuugiti mikroobikultuure 20 minutit 3000 tiiruga. Pealmine vedelik valati ära ja sade suspendeeriti ühe milliliitri $1 / 20 \mathrm{n}$ soolhappelahusega ja seejärel hoiti segu $10 \mathrm{~min}$. vesivannil $100^{\circ} \mathrm{C}$ juures. Selle aja jooksul toimus mikroobide ekstraktsioon ja segu neutraliseeriti: n/l naatriumhüdroksüüdilahusega. Suspensioonil neutraalse reaktsiooni määramise järel tsentrifuugiti seda uuesti ning pretsipitatsioonireaktsiooniks kasutati antigeeni sisaldavat vesiselget pealmist vedelikku.

Reaktsiooniks kasutati küülikutelt saadud lahjendamata ja lahjendatud $(1: 4)$ immuunseerumit. Katseklaasidesse pandi mikropipetiga $0,2 \mathrm{ml}$ seerumit ja lisati sama palju pretsipiteerivat antigeeni. Positiivse reaktsiooni korral tekkis $3-4$ minuti jooksul mōlema kihi vahele väike hall rõngas. Reaktsiooni hinnati,,++++++ vōi - . 


\section{Uurimistulemused}

Eesti NSV erinevates rajoonides hädatapetud või surnud punataudihaigetelt sigadelt isoleeritud 110 Erysipelothrix rhusiopathiae tüve hemaglutinatsiooni- ja pretsipitatsioonireaktsiooni tulemused on toodud tabelis 1 .

Tabel 1

Hemaglutinatsioonireaktsiononi seos pretsipitatsioonireaktsiooniga

\begin{tabular}{|c|c|c|c|c|}
\hline \multirow[b]{2}{*}{$\begin{array}{c}\text { Tüvede } \\
\text { arv }\end{array}$} & \multicolumn{2}{|c|}{ Hemaglutinatsioonireaktsioon } & \multicolumn{2}{|c|}{ Pretsipitatsioonireaktsioon } \\
\hline & Positiivne & Negatiivne & B-tüve seerumiga & $\begin{array}{c}\text { A-tüve seeru- } \\
\text { miga }\end{array}$ \\
\hline $\begin{array}{r}9 \\
100 \\
1\end{array}$ & $\frac{9}{-}$ & $\begin{array}{r}100 \\
1\end{array}$ & $\frac{9}{-}$ & 100 \\
\hline
\end{tabular}

Tabelis esitatud 101 hemaglutineerumata Erysipelothrix rhusiopathiae tüve hulgas leidus küll mitu tüve, mis hemaglutineerisid esimesel katsel nõrgalt võ̃i isegi keskmiselt, kuid ei hemaglutineerinud enam korduskatsetel mõni kuu hiljem.

Hemaglutinatsioon oli kõige tugevam $20--24$ tunni vanustel mikroobikultuuridel. Samade tüvede 48-tunnilistel mikroobikultuuridel oli hemaglutinatsioon märksa nõrgem või puudus üldse. 72 ja 96 tunni vanustel mikroobikultuuridel oli hemaglutineeriv omadus täiesti kadunud.

Erysipelothrix rhusiopathiae tüvede hemaglutineeriv omadus on seotud mikroobirakkudega, sest vastava tüve puljongkultuur annab positiivse hemaglutinatsioonireaktsiooni ka pärast tsentrifuugimist ja pealmise vedeliku asendamist steriilse füsioloogilise keedusoolalahusega. Hemaglutinatsioonireaktsiooni aga on võimalik läbi viia ainult mikroobide puljongkultuuridega, mitte agarplaatidel kasvanud ja sealt steriilse füsioloogilise keedusoolalahusega vối puljongsöötmega ärauhutud mikroobisuspensioonidega.

Hemaglutinatsioonireaktsiooni läbiviimiseks puljongkultuurides kasvatatud Erysipelothrix rhusiopathiae tüvedega on tarvis teatud eeltingimusi. Kõige paremini toimub hemaglutinatsioonireaktsioon, kui uuritavaid mikroobe kasvatatakse $2 \%$-lises lihapeptoonpuljongis, millele on lisatud $10 \%$ hobusevereseerumit. Veisevereseerum selleks otstarbeks ei kõlba. Dinteri [ ${ }^{?]}$ ja Iljašenko [ $\left.{ }^{5}\right]$ soovitatud laktoosi sisaldav sööde $10 \%$-lise hobusevereseerumiga ei andnud siin paremaid tulemusi, nagu ka Rootsi ja Venske $\left[{ }^{13}\right]$ soovitatud lihapeptoonpuljong $4 \%$-lise peptooniga ilma hobusevereseerumita ci andnud häid tulemusi.

Dinteri $\left.{ }^{[}{ }^{9}\right]$ ja Radvila $\left.{ }^{12}\right]$ seisukoht on, et iga kana erütrotsüüdid hemaglutinatsioonireaktsiooniks ei sobi. Käesoleva töö piirides katsetati pulloroosihaigete kanade erütrotsüütidega ja selgus, et need ei kõlba. Pulloroosihaígete kanade erütrotsüütide kasutamisel oli reaktsiooni tulemus palju nôrgem kui tervete kanade erütrotsüütide puhul.

Dinteri [ $\left.{ }^{9}\right]$ andmeil esineb hemaglutinatsioon siis, kui söötme $\mathrm{pH}$ kõigub $5-8$ piirides; kui $\mathrm{pH}$ on alla 4,5 ja üle 9,5 , kaob hemaglutinatsioon täiesti. Käesolevas töös kasutati söötmeid, mille pH oli 7,6. 20-24 tunnilise inkubeerimise järel, s. o. hemaglutinatsioonireaktsiooni läbiviimise ajaks, oli söötme $\mathrm{pH}$ langenud 7,2-7,1-ni, 48-tunnilise inkubeerimise järel üksikutel mikroobikultuuridel aga koguni 6,8-7,0-ni, kusjuures hemaglutinatsioonireaktsiooni tulemus oli vaid õige nõrgalt positiivne või koguni negatiivne. Nagu eespool märgitud, puudus 72 ja 96 tundi inkubeerunud puljongkultuuridel hemaglutineeriv omadus täiesti ja söötme $\mathrm{pH}$ oli langenud 6,6-6,8-ni. 
Ka Gelenczei ja Szent Iványi $\left[{ }^{10}\right]$ märgivad, et neil ei õnnestunud hemaglutinatsioonireaktsiooni läbiviimine mikroobikultuuridega siis, kui neid oli kasvatatud söötmeles, mille pH oli inkubeerimise alguses $7,0-7,2$.

Erysipelothrix rhusiopathiae tüvede hemaglutineeriva omaduse spetsiifilisuse kindlakstegemiseks lisandati mikroobikultuuride lahjendile enne kanaerütrotsüütide lisamist küülikutelt saadud immuunseerumit ja punataudivastast immuunseerumit (viimane valmistatud Vitebski biovabrikus). Kontrolliks kasutati paratüüfuse ning sigade katku vastast seerumit ja ka punataudi vastu kaitsesüstitud või kaitsesüstimata sigadelt saadud seerumit. Uurimistulemused on toodud tabelis 2 .

Tabel 2

Hemaglutinatsiooni pidurdus mitmesuguste seerumitega

\begin{tabular}{|c|c|c|c|c|c|c|c|c|c|}
\hline \multirow{2}{*}{ Seerumi liik } & \multicolumn{9}{|c|}{ Hemaglutinatsiooni pidurdus seerumi lahjendites } \\
\hline & $1: 5$ & $1: 10$ & $1: 20$ & $1: 40$ & $1: 80$ & $1: 160$ & $1: 320$ & $1: 640$ & $1: 1280$ \\
\hline \multicolumn{10}{|l|}{$\begin{array}{l}\text { Punataudivastane seerum } \\
\text { seeria } 16\end{array}$} \\
\hline $\begin{array}{l}\text { seeria } 16 \\
\text { seeria } 27\end{array}$ & - & $\overline{-}$ & $\overline{-}$ & $\underline{-}$ & - & $\overline{-}$ & $\begin{array}{c}++ \\
+++\end{array}$ & $\begin{array}{l}+++ \\
+++\end{array}$ & $\begin{array}{l}+++ \\
+++\end{array}$ \\
\hline seeria 51 & $\overline{-}$ & - & - & $\overline{-}$ & - & $\overline{-}$ & Th & ++ & ++ \\
\hline küülikult 1481 & - & - & - & - & - & - & $\overline{t+}$ & $\overline{+}+$ & $\begin{array}{l}t++ \\
++t\end{array}$ \\
\hline $\begin{array}{l}\text { küülikult } 921 \\
\text { küülikult } 18\end{array}$ & $\overline{-}$ & $\overline{-}$ & $\overline{-}$ & $\overline{-}$ & $\overline{-}$ & $\overline{t+}$ & $\begin{array}{l}+t \\
+++\end{array}$ & $\begin{array}{l}+++ \\
+++\end{array}$ & $\begin{array}{l}+++ \\
+++\end{array}$ \\
\hline \multicolumn{10}{|c|}{\begin{tabular}{l|l} 
Sigade katku vastane see- \\
rum (kontroll)
\end{tabular}$++++t+$} \\
\hline $\begin{array}{l}\text { Paratüüfusevastane see- } \\
\text { rum (kontroil) }\end{array}$ & + \pm \pm & +++ & +++ & +++ & +++ & $+t+$ & +++ & +++ & +++ \\
\hline \multicolumn{10}{|l|}{$\begin{array}{l}\text { Vaktsineeritud sigade see- } \\
\text { rumid }\end{array}$} \\
\hline $\begin{array}{l}\text { siga } 398 \\
\text { siga } 396\end{array}$ & $\overline{-}$ & $\overline{-}$ & $\overline{-}$ & $\stackrel{++}{-}$ & $\begin{array}{c}t+t \\
++\end{array}$ & $\begin{array}{l}+++ \\
+++\end{array}$ & $\begin{array}{l}+++ \\
+++\end{array}$ & $\begin{array}{l}+++ \\
+++\end{array}$ & $\begin{array}{l}+++ \\
+++\end{array}$ \\
\hline siga 401 & - & - & - & ++ & +++ & +++ & +++ & +++ & +++ \\
\hline siga 405 & - & & & & $\pm t$ & +++ & +++ & +++ & \\
\hline \multicolumn{10}{|l|}{$\begin{array}{l}\text { Vaktsineerimata sigade } \\
\text { seerumid }\end{array}$} \\
\hline $\begin{array}{l}\text { siga } 368 \\
\text { siga } 370\end{array}$ & $\begin{array}{l}+++ \\
+++ \\
+++\end{array}$ & $\begin{array}{l}+++ \\
+++\end{array}$ & $\begin{array}{l}+++ \\
+++ \\
+++\end{array}$ & $\begin{array}{ll}t+t+2 \\
++t \\
+t+\end{array}$ & 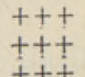 & $\begin{array}{l}t++ \\
+++ \\
++t\end{array}$ & $\begin{array}{l}l_{1} \\
+++ \\
+++\end{array}$ & $\begin{array}{l}+++ \\
+++ \\
+++\end{array}$ & $\begin{array}{l}+++ \\
+++ \\
+++\end{array}$ \\
\hline siga 371 & & & +++ & ++ & & ++ & $++t$ & $++t$ & \\
\hline
\end{tabular}

Pretsipitatsioonireaktsiooniga jagunesid uuritud 110 Erysipelothrix rhusiopathiae tüve põhiliselt kahte erinevasse seroloogilisse rühma, samuti nagu hemaglutinatsioonireaktsiooni puhul (vt. tabeleid 1 ja 3). Oks mittehemaglutineeriva tüvega teostatud pretsipitatsioonireaktsioon ei andnud positiivset reaktsiooni kummagi rühma immunnseerumiga ja tuleb arvata nn. N-variantide hulka $\left[{ }^{7}, 14\right]$.

Hemaglutinatsioonireaktsiooni positiivsed tulemused langevad ühte pretsipitatsioonireaktsiooni tulemustega vaid sel juhul, kui vastavaid Erysipelothrix rhusiopathiae tüvesid on kasvatatud S-vormina. Uuritud Erysipelothrix rhusiopathiae $\mathrm{R}$-vormi tüved hemaglutineerisid märksa nõrgemini või hoopiski mitte. Gelenczei ja Szent Iványi $\left.{ }^{10}\right]$ andmeil esineb ka mõningaid tüvesid, mis hemaglutineerivad R-vormina palju tugevamini kui S-vormina.

Võrreldes käesolevas töös saadud Erysipelothrix rhusiopathiae tüvede jagunemist seroloogiliste variantide järgi näeme, et B-variantide arv ühtib enam-vähem Dinteri $\left[{ }^{2}\right]$ ja Radvila ${ }^{\left[{ }^{12}\right]}$ andmetega, kuna Dedié $\left.{ }^{7}\right]$, Szent Iványi $\left.{ }^{14}\right]$ ning Rootsi ja Venske $\left.{ }^{13}\right]$ andmeil oli nende tüvede leiuprotsent 
Tabel 3

Seroloogiliste tüüpide seos pretsipitatsiooni- ja hemaglutinatsioonireaktsiooni puhul

\begin{tabular}{|c|c|c|c|c|c|c|c|c|c|}
\hline \multirow{3}{*}{$\begin{array}{l}\text { Tüvede ja im- } \\
\text { muunseerumite } \\
\text { tüüpide nimetus }\end{array}$} & \multicolumn{4}{|c|}{ Pretsipitatsioonireaktsioon } & \multicolumn{5}{|c|}{ Hemaglutinatsioonireaktsioon } \\
\hline & \multicolumn{4}{|c|}{$\begin{array}{l}\text { Pretsipiteeriv antigeen } \\
\text { tüvedest }\end{array}$} & \multicolumn{5}{|c|}{ Mikroobikultuuride lahjendid } \\
\hline & B Rakvere & $\begin{array}{l}\text { B Pärnu } \\
716\end{array}$ & A 328 & A 22 & $1: 2$ & $1: 4$ & $1: 8$ & $1: 16$ & $1: 32$ \\
\hline $\begin{array}{l}\text { B Rakvere } \\
\text { B Pärnu } \\
716 \\
\text { A } 328 \\
\text { A } 22\end{array}$ & $\begin{array}{c}+++ \\
+++ \\
- \\
-\end{array}$ & $\begin{array}{c}+++ \\
+++ \\
- \\
-\end{array}$ & $\begin{array}{c}- \\
- \\
+++ \\
+++\end{array}$ & $\begin{array}{l}-\overrightarrow{+} \\
++ \\
+++\end{array}$ & $\begin{array}{c}++++ \\
++++ \\
-\end{array}$ & $\begin{array}{c}++++ \\
++++ \\
- \\
-\end{array}$ & $\begin{array}{c}+++ \\
++ \\
-\end{array}$ & $\begin{array}{l}+ \\
++ \\
- \\
-\end{array}$ & $\begin{array}{l}- \\
- \\
-\end{array}$ \\
\hline
\end{tabular}

palju suurem. Erinevate resultaatide peamiseks põhjuseks on asjaolu, et viimati mainitud autorid on uurinud peamiselt värskelt isoleeritud Erysipelothrix rhusiopathiae tüvesid. Nagu käesolev uurimus näitab, lakkavad tüved, mis algul hemaglutineerivad, hiljem korduskatsel hemaglutineerimast. Selle põhjuseks on sageli ümberkülvide tagajärjel tüvede S-vormi muutumine R-vormiks ning igas tüves erineval hulgal leiduvate A- ja B-antigeenidega mikroobide vahekorra muutumine $\left[{ }^{13}\right]$. Nii said Roots ja Venske Erysipelothrix rhusiopathiae tüvede üksikkolooniate ümberkülvidega vähendada või suurendada ühe või teise antigeeni osatähtsust mikroobitüvedes, mille tagajärjel seal lõpuks oli kas ainult A- või ainult B-antigeene. Selletõttu ongi seletatav, miks üks punataudi tekitaja tüvi algul hemaglutineerib, kuid hiljem korduvatel ümberkülvidel selle omaduse kaotab.

Nagu antud uurimusest selgub, jagunevad ka Eesti NSV eri rajoonidest kogutud Erysipelothrix rhusiopathiae tüved kolme rühma, mis oma antigeenstruktuurilt üksteisest erinevad. Küülikutelt saadud hemaglutineeruvate tüvedega immuunseerumitega positiivse pretsipitatsioonireaktsiooni landnud tüved kuuluvad seroloogiliselt B-varianti [, 14 jt.], kuna ülejäänud tüved, peale ühe, kuuluvad A-varianti. Oks Erysipelothrix rhusiopathiae tüvi, mis ei hemaglutineerinud ega andnud positiivset pretsipitatsioonireaktsiooni ei A- ega B-variandi immuunseerumitega, tuleb arvata kolmandasse rühma, nimelt $\mathrm{N}$-variantide hulka.

Käesolev uurimus näitab, et hemaglutinatsioonireaktsiooni võib kasutada edukalt lihtsama ja kiirema meetodina pretsipitatsoonireaktsiooni asemel immunogeensete omadustega Erysipelothrix rhusiopathiae tüvede väljavalimiseks nii teaduslikuks kui ka praktiliseks otstarbeks. On vaja teha täiendavaid katseid, selleks et kindlaks teha hemaglutinatsiooni pidurdustesti kasutamise sobivust imuunsusastme määramiseks immuniseeritud loomadel.

Territoriaalselt paiknesid B-variandi tüved järgmiselt: Viljandi rajoonist 5, Rakvere rajoonist 1 , Pärnu rajoonist 1 ja Tartu rajoonist 2 tüve. Erysipelothrix rhusiopathiae B-variandi tüved isoleeriti nimetatud rajoonides individuaalseapidajate sigadelt, välja arvatud 2 tüve Viljandi rajoonist.

\section{KIRJANDUS}

1. Бучн е в К Н., Об убитой полужидкой формолвакцине рожи свиней. Ветерннария, $26,1949,10,1 \mathrm{k} .23-25$.

2. Г л у ховце в Г. Д.. Гидрооксильалюминиевая формолвакцина против рожи свиней. Ветеринария, 28, 1951, 3, lk. 47-52.

3. Г л уховц е в Г. Д., Методы активной профилактики рожи свиней. Труды Госуд. научно-контрольн. инст. вет. препаратов, Том IV, 1953, 1k. 236-245. 
4. Горл ов Б. В., Изучение иммуногенных свойств штаммов рожи свиней и принципы отбора их для производства. Труды Госуд. научно-контрольн. инст. вет. препаратов, Tом IV, 1953, lk. 246-256.

5. Иль яшенко M. А., Реакция преципитация, как метод отбора иммуногенных штаммов возбудителя рожи свиней. Диссертация, ВИЭВ, Москва, 1951.

6. Муромцев С. Н. и М а тв и енк. Испытание полужидкой формолвакцины против рожи свиней. Советская ветеринария, 1936, 11, 1k. 56-61.

7. Dedi'é, K., Die säuerlöslichen Antigene von Erysipelothrix rhusiopathiae. Monatshefte f. Veterinärmedizin, 4, 1949, 1, lk. 7-i0.

8. Di n te r, Z., Ober die haemagglutinative Aktivität des Rotlaufbakteriums. Tierärztliche Umschau, 3, 1948, 9/10, 1k. 143.

9. Dinter, Z., Der Haemagglutinationstest als eine Hilfsmethode bei der Bestimmung immunogener Rotlaufstämme. Berl. u. Münch. tierärztl. Wschr., 1949, 12, lk. $177-179$.

10. Gelenczei, E. und $\mathrm{Sz}$ e n t Ivány i, Th., Zur Hämagglutinationsfähigkeit der Rotlaufstäbchen. Acta Veterinaria Acad. Scient. Hungaricae, T. 1, 1951, lk. 55-62.

11. Hirst, G. K., The Agglutination of Red Cells by Allantoic Fluid of Chick Embryos Infected with Influenza Virus. Science, 94, 1941, 2427, 1k. 22-23.

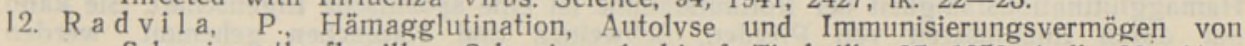
Schweinerotlaufbazillen. Schweizer Archiv f. Tierheilk,, 95, 1953, 1, lk. 33-44.

13. Roots, E. und Venske, W., Serologische und immunogene Eigenschaften der Erysipelothrix rhusiopathiae (E. muriseptica). Berl. u. Münch. tierärztl. Wschr., $65,1952,9,1 k .184-187,10$, 1k. 208-209 ja 11, 1k. 223-225.

14. Szent Iványi, Th., Die Typen des Rotlaufstäbchens und ihre Verbreitung in Ungarn. Acta Veterinaria Acad. Scient. Hungaricae, T. II, 1952, Fasc. 1-2, lk. $109-120$.

15. W a t t s, P. S., Studies on Erysipelothrix Rhusiopathiae. Journal of Pathology and Bacteriology, 50, 1940, lk. 355-369.

Eesti NSV Loomakasvatuse ja Veterinaaria Teadusliku Uurimise Instituut
Saabus toimetusse

2. I 1957

\title{
СЕРОЛОГИЧЕСКОЕ ИССЛЕДОВАНИЕ ШТАММОВ ВОЗБУДИТЕЛЯ РОЖИ СВИНЕИ
}

\author{
В. В. Тильга, \\ кандндат ветеринарных наук
}

Резюме

Для выяснения антигенной структуры местных штаммов возбудителя рожи свиней было изучено 110 штаммов Erysipelothrix rhusiopathiae, изолированных в различных районах Әстонской ССР. Данные реакции преципитации показали, что выделенные штаммы относятся к 3 различным антигенным вариантам. Девять $(8,2 \%)$ изолированных штаммов Erysipelothrix rhusiopathiae относились к Б-варианту (по Ильяшенко к А-варианту), $100(90,9 \%)$ к А-варианту (по Ильяшенко к Б-варианту) и один $(0,9 \%)$, не содержащий антигенных компонентов А- и Б-вариантов, к варианту N (по Ильяшенко к В-варианту).

Штаммы Б-варианта, обладающие сильными иммуногенными свойствами, дают положительную реакцию гемагглютинации (табл. 1). Для этой реакции были использованы лишь С-формы выделенных штаммов, культивированных в течение $20-24$ часов в $2 \%$-м МПБ с добавлением $10 \%$ лошадиной сыворотки (pH 7,6$)$. Специфичность реакции гемагглютинации была доказана при помощи торможения гемагглютинации как иммунной сывороткой, применяющейся при леченни, так и иммунной сывороткой вакцинированных свиней и кроликов.

Судя по данным работы, реакцию преципитации пфи определении иммуногенных снойств штаммов Erysipelothrix rlusiopathiae для научных и практических целей можно заменить реакцией гемагглютинации, методика которой является более простой и ускоренной. 


\title{
VON DER SEROLOGISCHEN UNTERSUCHUNG DER ROTLAUFSTAMME DER SCHWEINE
}

\author{
W. Tilga
}

\section{Zusammenfassung}

An 110 notschlachteten und an Rotlauf gestorbenen Schweinen aus verschiedenen Bezirken der Estnischen SSR wurden Versuche angestellt, um auf Grund der serologischen Eigenschaften der Rotlaufstämme ihre Varianten abzugrenzen. Von den 110 isolierten Stämment liessen sich nach Präzipitation $9(8,0 \%)$ zu der B-Variante, 100 $(90,9 \%)$ zu der A-Variante und $1(0,9 \%)$ Stamm, der weder mit den A-Seren, noch mit den B-Seren reagierte, zu der N-Variante zählen.

Die Stämme der B-Variante, die gute immunogene Eigenschaften haben, zeigen stets positive Reaktion der Hämagglutination. $\mathrm{Zu}$ dieser Reaktion wurden nur die S-Formen der Stämme benutzt. Die Bakterienstänme wurden in $2 \%$-iger Peptonbouillon mit einem Zusatz von $10 \%$ Pferdeserum $(\mathrm{pH} 7,6) 20-24$ Stunden lang bei $37^{\circ} \mathrm{C}$ gezüchtet. Diese Hämagglutinationsfähigkeit der Rotlaufstämme ist eine spezifische Eigenschaft. Sie kann nur durch Immunseren von Pferden, Schweinen und Kaninchen gehemmt werden (Tabelle 2).

Auf Grund der Untersuchungsergebnisse kann man sagen, dass die Hämagglutinationsreaktion es ermöglicht, schnell und verhältnismässig einfach eine prozentual kleine Gruppe (B-Variante) von Rotlaufstämmen $\mathrm{zu}$ wissenschaftlichen und praktischen Zwecken auszuwählen.

\section{Institut für Tierzucht und Veterinärkunde} der Estnischen SSR 